\title{
AC 2008-2401: A NANOTECHNOLOGY EXPERIMENT FOR UNDERGRADUATE ENGINEERING PROGRAMS: CARBON NANOTUBE PRODUCTION USING ELECTRIC DISCHARGE MACHINING
}

\section{Nebojsa Jaksic, Colorado State University-Pueblo}

Nebojsa I. Jaksic received the Dipl. Ing. degree in electrical engineering from Belgrade University in 1984, the M.S. in electrical engineering, M.S. in industrial engineering, and Ph.D. in industrial engineering from the Ohio State University in 1988, 1992, and 2000, respectively.

From 1992 to 2000 he was with DeVry University in Columbus, OH. In 2000, he joined Colorado State University-Pueblo, where he is currently an Associate Professor. Dr. Jaksic's interests include nanotechnology and mechatronics education and research. He is a member of ASEE, MRS, SME and IEEE. 


\title{
A Nanotechnology Experiment for Undergraduate Engineering Programs: Carbon Nanotube Production using Electric Discharge Machining
}

\begin{abstract}
A novel experiment for an undergraduate engineering course, the Engineering of Manufacturing Processes is described. The experiment demonstrates a process of manufacturing carbon nanotubes using a variation of the arc discharge method. Carbon nanotubes are synthesized in oil by electric discharge machining using two graphite electrodes. Pedagogical justifications and sustainability of the experiment within an undergraduate engineering curriculum are addressed.
\end{abstract}

\section{Introduction}

In Spring 2004 and 2005 semesters a nanotechnology course was offered to junior/senior industrial engineering students. A three-week lecture portion of the course was dedicated to carbon nanotubes. Engineering students taking the course expressed interest in imaging carbon nanotubes. However, the cost of carbon nanotubes and instrumentation were prohibitive factors in implementing such an experiment.

In literature, carbon nanotubes are produced using an arc discharge method in various media like helium, liquid nitrogen, water and sodium chloride. Our research group devised a novel arc discharge method to produce carbon nanotubes in oil using electrical discharge machining, an over 50-year old technology. This discovery presented an opportunity to develop an undergraduate experiment dealing with synthesis of carbon nanotubes.

\section{Justification}

Carbon nanotubes, with their extraordinary mechanical, electrical and thermal characteristics, are on the forefront of nanotechnology commercialization. They are used in highend bicycle frames, baseball bats, and hockey pucks, while carbon nanotube applications in computer monitors or energy storage devices are in developmental stages ${ }^{1}$. A Materials Today report $^{2}$ on the top ten advances in materials science placed five nanotechnology topics among them, including carbon nanotubes. This increased importance of carbon nanotubes as an engineering material justifies their inclusion in undergraduate engineering education. In general, there exists a need to create sustainable nanotechnology modules within current engineering curricula and within required engineering courses. While many nanotechnology topics can be integrated without much difficulty into materials engineering curricula, this integration is often a challenge in other engineering disciplines. Carbon nanotube manufacturing topics could be integrated within manufacturing processes courses that exist as required courses in many undergraduate mechanical or industrial engineering programs. 
Pedagogically, engineering laboratory experiments are typical examples of active learning. Depending on the course objectives, the laboratory experiments are either of a cookbook type where students follow a set of instructions and all produce similar results, an organized project type where the instructions are not precise and allow for some creativity, an open-ended project type where the course instructor has a reasonable knowledge of the final outcome, or research where neither the students nor the instructor know the final outcome of the experiments. The described experiment falls in the organized project type category since the given instructions are not precise. In addition, the steps whereby students analyze the obtained results, compare them with the results obtained by using an empirical formula for a similar process, and draw their conclusions by either justifying their results or augmenting the formula from a similar process to fit their data, classify the method of this experiment as a discovery-based learning.

Justification of active discovery-based learning methods in engineering education, and specifically the methods used in the described nanotechnology experiment, are based on McCarthy's ${ }^{3}$ version of the $\mathrm{Kolb}^{4}$ learning cycle motivated in part by Harb et $a l^{5}$. Kolb and McCarthy proved that one could learn new concepts by following a repetitive pattern, the learning cycle, in which one performs sets of activities to ask and answer the questions why, what, how, and what if associated with the material. In engineering, active discovery-based learning is considered an important part of this learning cycle ${ }^{6}$. In Bruner ${ }^{7}$, discovery learning is defined as a cognitive instructional model whereby students are empowered and encouraged to learn concepts and principles through active hypothesis testing and discovery, just as during the described experiment.

ABET (Accreditation Board for Engineering and Technology) EAC (Engineering Accreditation Commission) has developed a set of accreditation criteria ${ }^{8}$ for all undergraduate engineering programs. Criterion 3 deals with program outcomes and assessment whereby students at graduation must be able to demonstrate having certain abilities, knowledge, and understanding. The described nanotechnology experiment addresses students' abilities to engage in life-long learning by presenting a need to learn new technologies and by actively engaging students in one of them.

\section{Previous Work}

In graduate-level education, there are many courses dealing with various nanotechnology topics. However, there are fewer successful attempts in presenting this material to the undergraduate student population, and then mostly to science majors like physics or chemistry. Furthermore, in undergraduate engineering curricula there are only a handful of isolated reports addressing nanotechnology topics ${ }^{9-13}$. Even then, the courses offered are mostly stand-alone optional courses not taken by all students in the program. The evolution of nanotechnology education in the Engineering Department at from 2002 to

2006 is reported in $^{13}$. The article includes undergraduate and graduate courses with nanotechnology topics as well as a review of undergraduate and graduate research projects. An upper-level three credit-hour undergraduate nanotechnology course with a strong emphasis on design-based learning was offered in the spring semester of 2005 and $2006^{13,14}$. A three-week lecture portion of the course was dedicated to carbon nanotubes. Since an accompanying 
laboratory exercise did not exist, the enrolled students expressed interest in producing and imaging their own carbon nanotubes. At the same time, investigations of low-cost safe methods for the production of carbon nanotubes were the subject of two active research projects at the university $^{15,16}$. The nanotechnology experiment described in this work is based on the results and methods from these projects.

Carbon nanotubes are mostly produced by chemical vapor deposition ${ }^{17}$, laser ablation ${ }^{18}$, or arc discharge. Using the arc-discharge, carbon nanotubes are synthesized by striking an electric arc between two graphite electrodes in an inert atmosphere. High temperatures developed between the electrodes and high current densities allow formation of carbon nanotubes as deposits on the cathode as well as on the walls of a reaction chamber ${ }^{19}$. There are reported results on the arcdischarge method in various media like helium, argon, liquid nitrogen ${ }^{20}$, water ${ }^{21}$, and sodium chloride $^{22}$. Further research ${ }^{16}$ yielded a more suitable liquid for the arc-discharge method and a commercially available apparatus that can be quickly modified for carbon nanotube production. The liquid is one of the electric discharge machining (EDM) dielectric oils Cutzol EDM-500 used in electric discharge machines for material removal. Electric discharge machines (sinker type) have servo controllers for electrode gap regulation. Electric discharge machining (EDM) is a well-established nontraditional machining process ${ }^{23}$ taught in the Engineering of Manufacturing Processes course. An electric discharge machine schematic drawing is shown in Figure 1. The machine provides automatic control of the electrode height during arcing using a hydraulic servomechanism.

Preliminary developmental efforts ${ }^{24,25}$ in designing the carbon nanotube experiment emphasized the whole process including manufacturing and characterization. However, the time and equipment constraints were not adequately addressed. For example, an atomic force microscope in the Chemistry Department was used for material characterization. This created scheduling problems and required additional time to learn how to use the instrument.

\section{Curriculum Context}

The Engineering of Manufacturing Processes is a required three-hour lecture two-hour laboratory one-semester junior/senior course offered in the Industrial Engineering program at This course together with a computer-integrated manufacturing course constitutes the manufacturing course sequence. Nontraditional manufacturing processes are analyzed in the Engineering of Manufacturing Processes. Electric discharge machining processes are addressed. In one of the laboratory experiments students use the laboratory electric discharge machine to selectively remove material from a steel coin.

The nanotechnology experiment dealing with production of carbon nanotubes is implemented as a second experiment using the electric discharge machine. This active learning nanotechnology experiment is designed to enable students to gain hands-on knowledge in synthesizing carbon nanotubes. The experiment builds on students' previous experiences with existing machines in the engineering laboratory. In addition, the experiment is inexpensive and safe. Before the experiment, a single two-hour lecture dealing with the basics of nanotechnology, various carbon nanotube production methods, and their applications is delivered. 


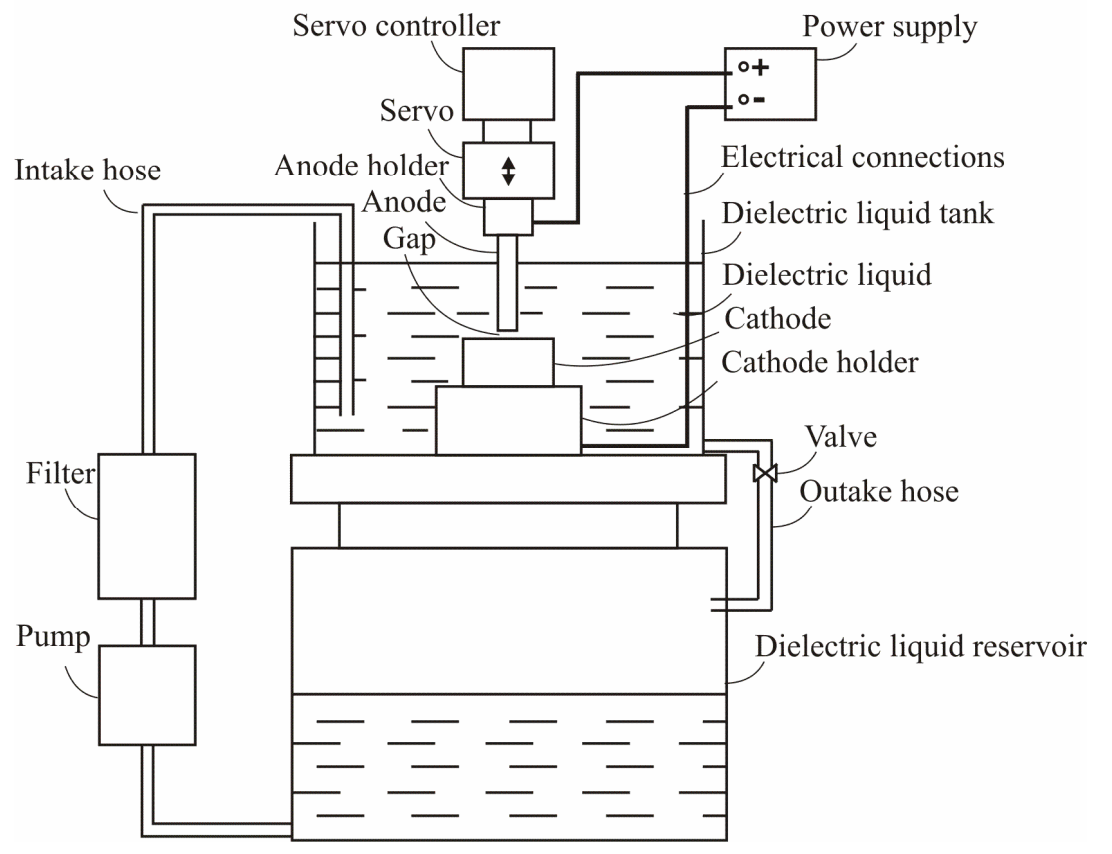

Figure 1. Schematic presentation of a conventional electric discharge machine

\section{Laboratory Assignment}

The main objective of this laboratory experiment is to provide students with a practical experience, and deeper understanding of one of the novel carbon nanotube manufacturing methods, the arc discharge using an electric discharge machine. At the completion of the experiment students should be able to:

1. Produce carbon nanotubes using a conventional electric discharge machine (This is a novel process and as such it presents a justification for life-long learning. New knowledge is created constantly. Engineers must be a part of this process);

2. Demonstrate an understanding of the critical process parameters in producing carbon nanotubes; and

3. Critically evaluate the above method for quality, quantity, and economic feasibility.

The laboratory task is specified after a lecture on nanotechnology, carbon nanotube production, characterization, and applications. Using an electric discharge machine with two carbon electrodes, the students, working in pairs, are to produce near-gram quantities of unrefined carbon nanotubes as deposits on the cathode. Students are instructed to use currents ranging from $5 \mathrm{~A}$ to $10 \mathrm{~A}(10 \mathrm{~A}$ is the maximum electric discharge machine current) and the voltage of about $20 \mathrm{~V}$ (process constraint) for the experiment. Furthermore, they are instructed to make sure that the voltage polarity is such that the cathode is the work piece. The electric discharge machine, in this case, should be set to "reverse polarity". This setting is not normally used for electric discharge machining. After the arc is started, students are to allow a cathode deposit 
buildup for a set amount of time (assigned values of 5, 10, 15, and 20 minutes to different student pairs) while constantly stirring the oil. A demonstration of the process without stirring the oil is performed by the instructor showing that the arc would extinguish itself within few minutes or the oil would be used in carbon nanotube synthesis. After their assigned time expires, students are to remove the deposit from the cathode. For this step, students are encouraged to use gloves, or remove some oil from the dielectric liquid tank to expose the deposit. Then, the students are to measure the weight of the removed deposit.

In a post-experiment laboratory report students should include an analysis of the results. In the analysis, they are to compare the weight of the removed carbon-nanotube rich deposit with the weight information obtained by using a published empirical formula for volumetric material removal rate in electric discharge machining ${ }^{22}$,

$$
\mathrm{M} R R=K \frac{I}{T_{m}^{1.23}}
$$

where MRR is metal removal rate in $\mathrm{mm}^{3} / \mathrm{s} ; \mathrm{K}$ is constant of proportionality equal to 664; $\mathrm{I}$ is discharge current in $\mathrm{A}$, and $\mathrm{T}_{\mathrm{m}}$ is melting point of work metal in ${ }^{\circ} \mathrm{C}$. While the published formula applies to a material removal process only, due to the nature of the process it can be extrapolated that the same process variables ( $\mathrm{I}$, and $\mathrm{T}_{\mathrm{m}}$ ) apply for carbon nanotube manufacturing. The empirical material removal rate formula is to be augmented as the results dictate. Based on the current prices of carbon, and the cost of electrical energy as found from students' electrical bills, an economical analysis is to be performed to calculate the cost of produced carbon nanotubes.

\section{Results}

In the experiment, an electric discharge machine using a graphite electrode and a graphite block submerged in dielectric oil generated a sustainable electric arc thus creating a nanotuberich cathode deposit. After removal from the dielectric liquid tank, this deposit was submerged in acetone to remove any residual oil from it. Then, it was dried and weighted. The experiment was limited from 5 to 20 minutes of arcing per student pair. Student pairs were assigned 5, 10, 15, or 20 minutes of arcing. Figure 2 shows an experiment in progress. Figure 3 depicts a 0.3 gram deposit obtained at a current of 10A and an arc lasting 15 minutes. Each student pair was able to perform the experiment and obtain a certain amount of carbon nanotube-rich deposit.

Students analyzed the results of their experiments in their laboratory reports. Based on the values of their process variables like current and arc duration, and material properties information such as graphite specific density of $1.7 \mathrm{~g} / \mathrm{cm}^{3}$, and carbon sublimation temperature of $3727{ }^{\circ} \mathrm{C}$, all students were able to apply the empirical formula for volumetric material removal rate in electric discharge machining and calculate the weight of the carbon removed. When compared with the actual deposits obtained in the experiments, the measured weight of the deposit was always lower than the calculated weight of the carbon removed. The difference between the weight of the deposit and the calculated removed weight was between $25 \%$ and $30 \%$. Two explanations with accompanying solutions were provided. One explanation was that the two processes are not similar enough so that the empirical formula for electric discharge machining does not apply. Thus, a new empirical formula should be derived based on extensive testing. The other explanation centered on the losses of carbon as the carbon ions were moving from one electrode to another. The oil flow carried some carbon away, thus not allowing all the removed material 
from the anode to be deposited onto the cathode. Students proposed to apply a different empirical formula by including a process efficiency term in the empirical formula for electric discharge machining. This augmented formula fits the data. Furthermore, one student pair questioned voltage as a process parameter. They claimed that the change in voltage could change the quantity of produced carbon nanotubes. This claim is based on the assumption that electrostatic forces are the predominant cause of carbon-nanotube deposit formation.

Economic analyses of the process differed mostly in the price of graphite used in electrodes. Some students priced technical pencil leads from the local book store at about $\$ 1 / \mathrm{g}$, while others priced bulk quantities of electrode graphite from the Web at about $\$ 0.05 / \mathrm{g}$. The electrical power consumption was estimated at about $0.18 \mathrm{KWhr} / \mathrm{g}$ of carbon nanotube deposit. At the price of about $0.1 \$ / \mathrm{KWhr}$ the total cost of one gram of carbon-nanotube deposit ranged from under 10 cents to over one dollar. Most of the students realized that currently available electric discharge machines would not be preferred devices for production of carbon nanotubes in kilogram quantities, but would work well for gram quantities.

Quality of carbon nanotubes, including their type, size, chirality, and concentration in the deposit were not addressed in the experiment. Such an evaluation would require specialized instrumentation like a scanning probe microscope, or a transmission electron microscope which are usually not available in undergraduate engineering programs. Instead, students had to accept the results from literature delivered in the lecture portion of the nanotechnology module.

At the time the laboratory reports were delivered back to students an additional analysis of their results was performed by the instructor. All students' results were presented together on a graph showing the time vs. weight of the deposit (experimental and calculated data). The current was normalized so that a two-variable graph could be drawn on the board. The results were consistent.

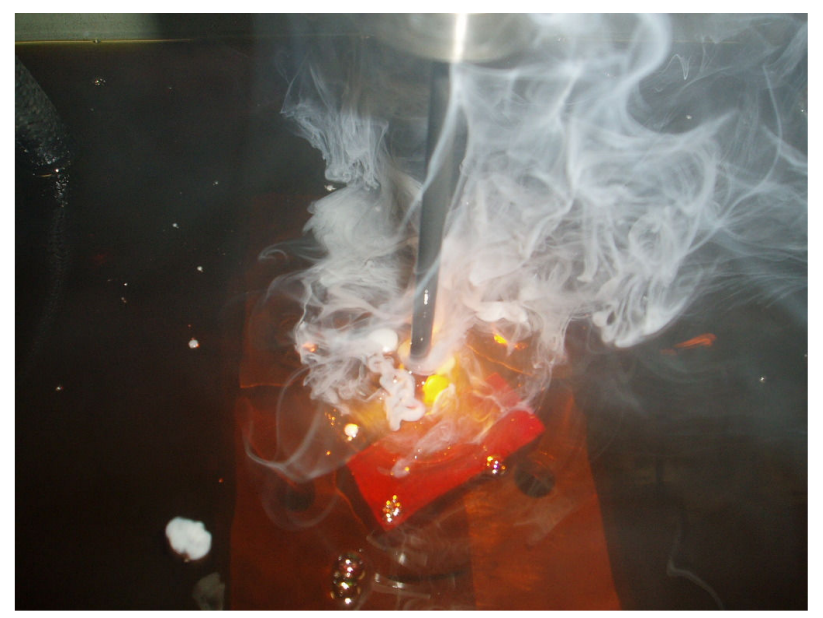

Figure 2. Carbon nanotube production using an electric discharge machine

At the end of each semester, for each course a student perception survey is administered by the university. Student comments for the carbon nanotube production laboratory were all positive. 
Since electric discharge machines are mass-produced, the experiment can be easily replicated. Also, there are advantages in using a familiar machine in novel ways.

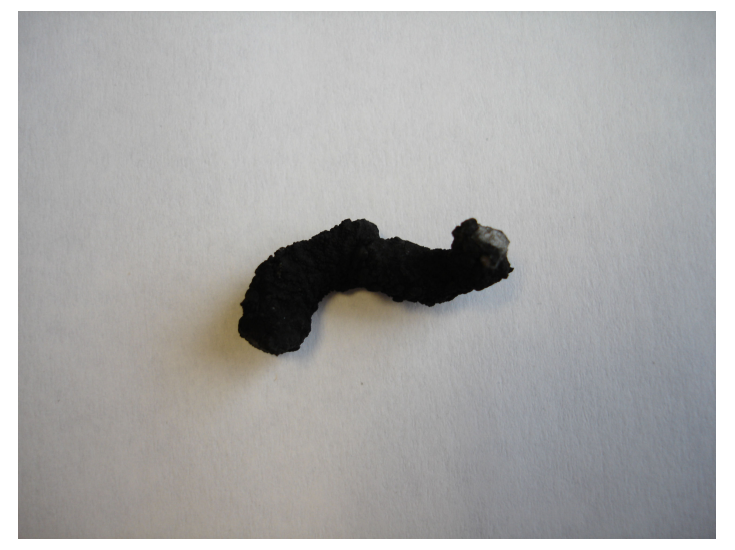

Figure 3. Typical carbon nanotube-rich deposit

\section{Conclusions}

In this work, a carbon nanotube synthesis laboratory experiment is presented with respect to a pedagogical context within an undergraduate engineering curriculum. The experiment is envisioned as an active discovery-based learning tool. Students produced near-gram quantities of carbon nanotube-rich deposits using electric discharge machining within minutes. They compared their results with the results obtained by using a formula used for a similar process. They discovered that the formula does not hold, so they augmented it to account for losses due to the oil flow between the electrodes. Thus, the discovery-based learning objectives dealing with the production of carbon nanotubes using electric discharge machining are satisfied. Student comments are positive. The described experimental setup is inexpensive and reproducible.

\section{Acknowledgments}

This project was supported in part by NSF Grant 0407289 .

\section{Bibliography}

1. M. Meyyappan, editor, Carbon Nanotubes Science and Applications, CRC Press, 2005.

2. Wood, J., "The top ten advances in materials science," Materials Today, vol. 11, No. 1-2, pp. 40-45, Jan-Feb. 2008.

3. B. McCarthy, The 4MAT System: Teaching to Learning Styles With Right/Left Mode Techniques: EXCEL, Inc., 1987.

4. D. A. Kolb, Experiential Learning: Experience as the Source of Learning and Development, Prentice Hall, 1984.

5. J. N. Harb, S. O. Durant, and R. E. Terry, "Use of the Kolb learning cycle and the 4MAT system in engineering education," Journal of Engineering Education, vol. 82, No. 2, April 1993, pp. 70-77.

6. L. Hotaling, R. Sheryll, and R. Stolking, "Discovery based learning in the engineering classroom using underwater robotics," Proceedings of the ASEE Annual Conference and Exposition, Session 2006-78, 2006. 
7. J. Bruner, Toward a Theory of Instruction, Harvard University Press, 1966.

8. Criteria for Accrediting Engineering Programs, Accreditation Board for Engineering and Technology, March 17, 2007. http://www.abet.org/Linked\%20Documents-UPDATE/Criteria\%20and\%20PP/E001\%200708\%20EAC\%20Criteria\%2011-15-06.pdf accessed on January 14, 2008.

9. J. D. Adams, B. S. Rogers and L. J. Leifer, "Microtechnology, nanotechnology, and the scanning-probe microscope: an innovative course ," IEEE Transactions on Education, vol. 47, No. 1, pp. 51-56, Feb. 2004.

10. J. A. Jaszczak and B. E. Seely, "Planting Seeds: Including Nanotechnology Education into Engineering Curricula," Materials Research Society 2006 Spring Meeting, Symposium KK, San Francisco, CA, April 17-21, 2006.

11. S. J. Lee, E. L. Allen, and L. He, "A Bottom-up Approach to Interdisciplinary Engineering Education in Nanotechnology," Materials Research Society 2006 Spring Meeting, Symposium KK, San Francisco, CA, April 17-21, 2006.

12. V. Mitin, X. Liu, D. Vo, H. Van, and A. Verevkin, Presentation: "Undergraduate AFM/STM Laboratory," The $3^{\text {rd }}$ International Seminar on Teaching Nanoscience with Scanning Probe Microscopy, Chicago, IL, March 28, 2007.

$13 . \quad$, "Nanoscience, Nanoengineering and Nanotechnology Education at "Materials Research Society 2006 Spring Meeting, Symposium KK, San Francisco, CA, April 17-21, 2006.

14. "A Design-Based Nanotechnology Course for Undergraduate Industrial Engineering Students," Industrial Engineering Research Conference, Orlando, Florida, May 20-24, 2006.

$15 . \quad$ "Health Risks in Multiwall Carbon Nanotube Production Using Arc Discharge in Liquid Nitrogen," Industrial Engineering Research Conference, Orlando, Florida, May 20-24, 2006.

16. Production of Multi-Wall Carbon Nanotubes using an Electrical Discharge Machine, M.S. Thesis, May 12, 2006.

17. B. Zheng, Y. Li and J. Liu, "CVD synthesis and purification of single-walled carbon nanotubes on aero gelsupported catalyst," Applied Physics A: Materials Science \& Processing 74(3), 345-348, 2002.

18. C. D. Scott, S. Arepalli, P. Nikolaev, and R. E. Smalley, "Growth mechanisms for single-wall carbon nanotubes in a laser-ablation process," Applied Physics A: Materials Science \& Processing 72(5), 573-580, 2001.

19. T. W. Ebbesen and P. M. Ajayan, "Large-scale synthesis of carbon nanotubes," Nature 358, 220-222, 1992.

20. S. H. Jung, M. R. Kim, S. H. Jeong, S. U. Kim, O. J. Lee, K. H. Lee, J. H. Suh, and C. K. Park, "High-yield synthesis of multi-walled carbon nanotubes by arc discharge in liquid nitrogen," Applied Physics A-Materials Science \& Processing 76, 285-286, 2003.

21. L. A. Montoro, C. Z. L. Renata, and J. M. Rosolen, "Synthesis of single walled and multi-walled carbon nanotubes by arc-water method," Carbon 43, 200-203, 2005.

22. S. D. Wang, M .H. Chang, K. M. Lan, C. Wu, J. Cheng, and H. Chang, "Synthesis of carbon nanotubes by arc discharge in sodium chloride solution," Carbon 43, 1792-1795, 2005.

23. M. P. Groover, Fundamentals of Modern Manufacturing: Materials, Processes, and Systems, Third Edition, Wiley, 2007.

$24 . \quad$ Presentation: "Nanotechnology in Manufacturing Processes Laboratory: Production of Carbon Nanotubes Using Arc-Discharge Method," The $3^{\text {rd }}$ International Seminar on Teaching Nanoscience with Scanning Probe Microscopy, Chicago, IL, March 28, 2007.

$25 . \quad$, "A Nanotechnology Experiment: Carbon Nanotube Synthesis in Electric Discharge Machines," ASEE Rocky Mountain Section Meeting, April 20, 2007. 